\title{
Povidone iodine: The new solution for mesothelioma?
}

\author{
Valerie W. Rusch, MD
}

See related article on pages 558-66.

In this issue of the Journal, Lang-Lazdunski and colleagues analyze the outcomes of 102 consecutive patients with malignant pleural mesothelioma (MPM) treated with a multimodality therapy program including extended pleurectomy and decortication, intraoperative hyperthermic povidone iodine pleural lavage, and adjuvant chemotherapy and targeted radiotherapy. They report favorable results, with overall median and 5-year survivals of 32 months and $23.1 \%$. Should this approach become widely accepted treatment for patients with MPM who are candidates for surgery?

Few cancers have engendered as much therapeutic nihilism as MPM. Considerable progress, however, has been made in this rare and difficult malignancy during the past 25 years. There have been significant advances in the methods of pathologic diagnosis and clinical staging, marked decreases in surgical morbidity and mortality, and improvements in chemotherapy and radiotherapy. Multiple clinical trials have shown the feasibility of combined modality therapy for patients who are candidates for surgical resection either with extrapleural pneumonectomy or lung-sparing extended pleurectomy and decortication. There is an increasing understanding of the molecular biology of MPM, with the result that a plethora of new "targeted therapies" and immunotherapy drugs are currently in clinical trials for this disease. Completely novel approaches to intrapleural therapy, such as sustained-release delivery of cisplatin, oncolytic viral therapy, and cell-based immunotherapy, are also currently in clinical trials for patients with MPM. As LangLazdunski and colleagues' study illustrates, the oft quoted median overall survival of 12 months no longer holds true for many patients with MPM. In reality, this is a banner time for laboratory and clinical studies in this disease.

The study of Lang-Lazdunski and colleagues also illustrates ways in which we can do better in studying MPM. Like many published studies, this one is

\footnotetext{
From the Thoracic Service, Department of Surgery, Memorial Sloan-Kettering Cancer Center, New York, NY.

Disclosures: Author has nothing to disclose with regard to commercial support.

Received for publication Oct 22, 2014; accepted for publication Oct 25, 2014; available ahead of print Nov 22, 2014.

Address for reprints: Valerie W. Rusch, MD, Thoracic Service, Department of Surgery, Memorial Sloan-Kettering Cancer Center, 1275 York Ave, New York, NY 10065 (E-mail: ruschv@mskcc.org).

J Thorac Cardiovasc Surg 2015;149:567-8

$0022-5223 / \$ 36.00$

Copyright (C) 2015 by The American Association for Thoracic Surgery http://dx.doi.org/10.1016/j.jtcvs.2014.10.109
}

retrospective, even though the treatment approach was relatively uniform. Globally, there are now enough centers of excellence treating MPM that multicenter prospective trials can be undertaken. Aside from several chemotherapy trials, only a few small surgically based multicenter trials have been completed. Additional larger trials are needed. The study of Lang-Lazdunski and colleagues evaluated multiple therapies, making it hard to determine which ones might be effective. Because almost $90 \%$ of first recurrences were in the ipsilateral pleura or lung, it seems unlikely that the povidone iodine lavage, though well tolerated, was particularly effective. At present, prospective trials in this disease need to be designed around clear, simple questions with clean end points so that we can understand which components of multimodality therapy are worth using and which should be discarded. For surgically based trials, the operations performed and the extent of resection should be clearly defined. ${ }^{1}$ Adverse events should be uniformly recorded according to internationally accepted definitions and severity grading standards, such as the Common Terminology Criteria for Adverse Events. ${ }^{2}$ More robust preclinical and initial clinical data should be available before incorporating a novel therapy into a multimodality regimen. The preliminary data supporting hyperthermic povidone iodine pleural lavage in this study, for example, were scant. It is also important to know how many patients screened for a study prove eligible and how many actually enroll. The denominator is rarely reported, and it leaves us wondering how broadly applicable a multimodality treatment regimen is for MPM.

The study of Lang-Lazdunski and colleagues also identifies several prognostic factors (eg, nodal status, tumor histologic type, extent of resection) that have consistently been reported as significant in other studies. ${ }^{3-5}$ Prognostic models are now refined enough to allow better patient selection and stratification for clinical trials. Treating all patients with MPM in the same manner is analogous to grouping together patients with stage Ia and those with stage IIIa non-small cell lung cancer in a single therapeutic study. To make progress, we need to adopt a more refined approach to studying patients with MPM.

Lang-Lazdunski and colleagues should be congratulated on implementing a consistent approach to the care of selected patients with MPM and on thoughtfully analyzing their results. Their ability to do this emphasizes the importance of patients with rare cancers like MPM being referred to centers of excellence that have multimodality expertise and are engaged in clinical research. Their experience is 
one of several studies that help us understand how to move forward in treating this challenging disease.

\section{References}

1. Rice D, Rusch V, Pass H, Asamura H, Nakano T, Edwards J, et al; International Association for the Study of Lung Cancer International Staging Committee and the International Mesothelioma Interest Group. Recommendations for uniform definitions of surgical techniques for malignant pleural mesothelioma: a consensus report of the International Association for the Study of Lung Cancer International Staging Committee and the International Mesothelioma Interest Group. J Thorac Oncol. 2011;6:1304-12.

2. US Department of Health and Human Services, National Institutes of Health, National Cancer Institute. Common Terminology Criteria for Adverse Events
(CTCAE), version 4 [Internet]. The Institute; 2010. Available at: http://evs.nci. nih.gov/ftp1/CTCAE/CTCAE_4.03_2010-06-14_QuickReference_8.5x11.pdf.

3. Herndon JE, Green MR, Chahinian AP, Corson JM, Suzuki Y, Vogelzang NJ. Factors predictive of survival among 337 patients with mesothelioma treated between 1984 and 1994 by the Cancer and Leukemia Group B. Chest. 1998;113: 723-31.

4. Rusch VW, Giroux D, Kennedy C, Ruffini E, Cangir AK, Rice D, et al; IASLC Staging Committee. Initial analysis of the International Association for the Study of Lung Cancer Mesothelioma Database. J Thorac Oncol. 2012;7: 1631-9.

5. Pass HI, Giroux D, Kennedy C, Ruffini E, Cangir AK, Rice D, et al. IASLC Staging Committee and Participating Institution. Supplementary prognostic variables for pleural mesothelioma: a report from the IASLC Staging Committee. J Thorac Oncol. 2014;9:856-64. 